\title{
Application Study of Resin Material in Optical Drive
}

\author{
Wei Guo ${ }^{1, a}$, Jianghua Zhang ${ }^{2, b}$
}

${ }^{1}$ Department of Mechanical Engineering, Dalian Vocational \& Technical College, Dalian, 116037, China

${ }^{2}$ College of Light Industry and Chemical Engineering, Dalian Polytechnic University, Dalian 116034, China

a'Guostephen@hotmail.com, bzhang_jh@dlpu.edu.cn

Keywords: Resin material, cost down, traverse base.

\begin{abstract}
In the optical recording equipment, the market price is decreasing year by year. Designers need to find new method to meet the tendency and keep their production profits. It makes the usage of resin material to be a trend in the industry. In this paper, by discussing the merits and demerits of resin material, we introduce the selection principle of resin material and give out a probable cost down effect.
\end{abstract}

\section{Introduction}

As most common household entertainment equipment, DVD player and BD player are very popular in families all over the world [1,2]. With the price reduce year by year, producers of these entertainment equipments feel increasingly pressure on cost control. Traverse Units of these entertainment equipments are very important parts in these equipments and they take a huge part of the equipment's cost. The traverse unit contains optical pickup unit, stepping motor, spindle motor, gears and gear rack etc.. All these parts are assembled onto traverse base [3]. When the equipment is working, the optical disc is placed onto spindle motor and it is turning in very high speed together with spindle motor. At the same time, optical unit is moving quickly fast to keep seeking the track on optical disc. These movements bring high frequency dynamic load to traverse base. Designers use metal material on traverse base to prevent the influence from shape change caused by thermal shock, drop, aging, etc. With material technology development and cost down requirement increase, there is a trend of using resin material to instead steel metal in traverse base design. In this paper, we want to find one perfect material for the traverse base of Blu-ray disc player, which need to show good stability and high strength when transporting and playing.

\section{Present Situation}

During the history of traverse base development, designers usually use steel material to keep a good strength and excellent performance. With the competition increase and price decrease, designers began to use thinner steel to cost down. The thickness of steel material is changed from $2.0 \mathrm{~mm}$ to $1.6 \mathrm{~mm}$, and it is now changed to $1.2 \mathrm{~mm}$ due to design cost down [4]. Also there is a trend to make huge hollow and bend reinforcement to decrease total weight with less strength lose.

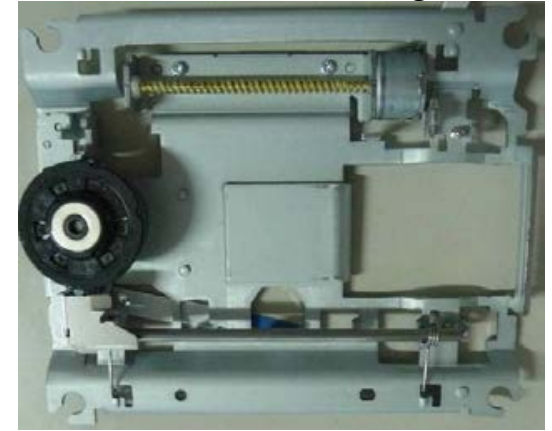

Fig. 1 The evolution of traverse base

(thickness $=1.6 \mathrm{~mm}$, design of counterweight plate with small hollow) 


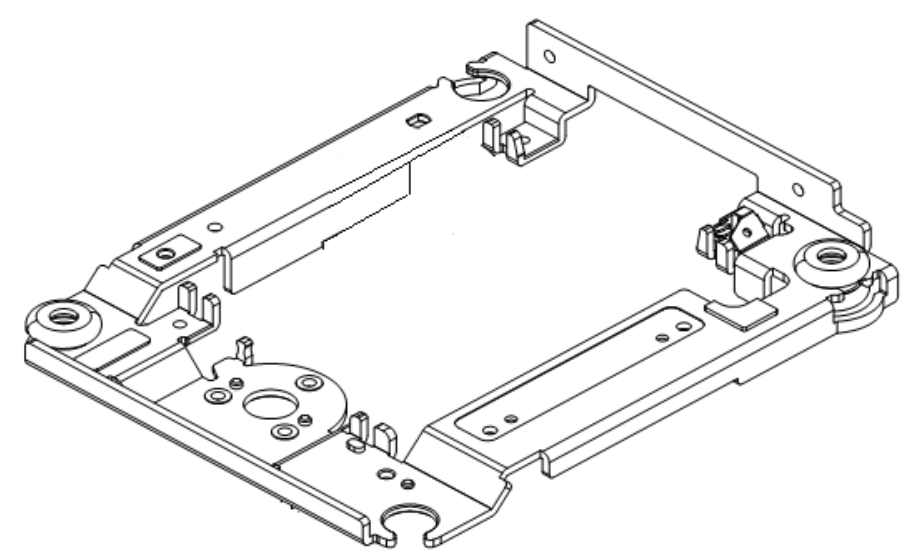

Fig. 2 The evolution of traverse base (thickness=1.6mm, large hollow + bend reinforcement design)

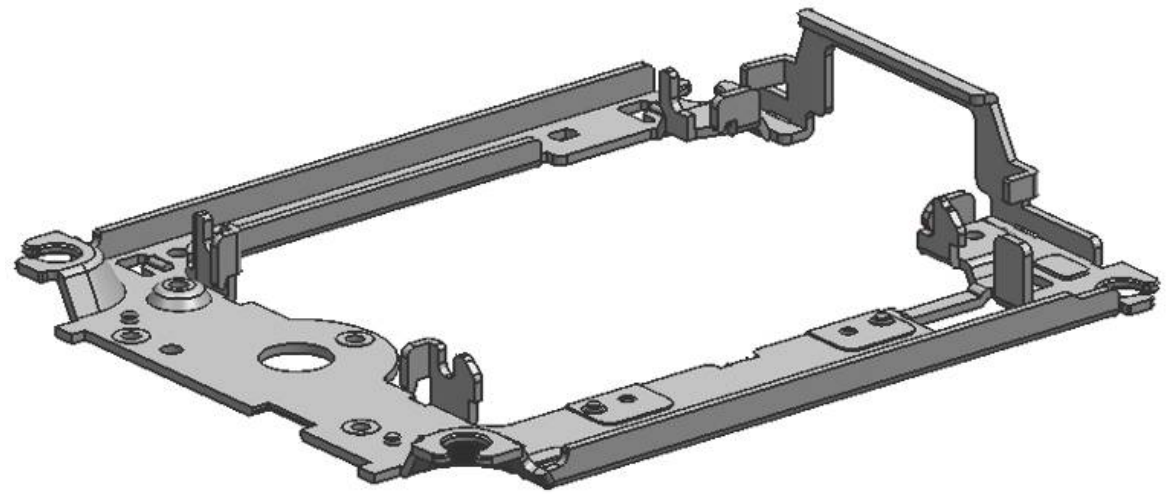

Fig. 3 The evolution of traverse base (thickness $=1.2 \mathrm{~mm}$, large hollow + bend reinforcement design)

\section{Advantage of Resin Material}

Compare with steel metal, resin material have below advantages:

(1)Reduce total mass. The specific gravity of resin material is much smaller than steel metal, normally $1.1 \mathrm{~g} / \mathrm{cm} 3 \sim 1.6 \mathrm{~g} / \mathrm{cm} 3$, about $1 / 6$ of the specific gravity of steel metal. This will decrease the total mass of traverse unit and reduce the impulse force.

(2)Increase the utilization rate of materials. When use hot runner system in injection molding, the utilization rate is over $95 \%$. At the same time, when use steel metal, the utilization ratio is no more than $50 \%$ in traverse base design.

(3)Generate complex shape. Use the characteristics of high fluidity in injection, we can design complex shape to reduce auxiliary components and auxiliary processes such as shaft, spring, tapping and riveting, which cannot be reduced in steel traverse base. It will also reduce assembling time due to less part assembled.

(4)Less prepare procedure. When use SECC in traverse base production, we usually need cleaning procedure after press production to remove press oil which is used in press production to keep product surface smooth. It will decrease this procedure when we use resin material. Also this will help preventing rust which is usually found in SECC material and its products.

\section{Demerits Of Resin Material}

Considering above advantages of resin material, why do not people consider resin material in the beginning of traverse unit design? This should attribute to the demerits of resin material:

(1)Most products which is produced with common resin material will have their dimensions change when put in high/low temperature for a long time. This will cause focus shift of optical lens and it will defocus from data surface of optical disc when optical disc playing [5]. 
(2)Usually strength of resin material is lower than steel material. It is much easier to encounter a drop problem, which is often happened in long distance transfer or in daily use.

\section{Recent Approach}

With rising energy, transport and labor squeezing profits, it is hard time for manufacturers, especially for the international brands. There raises a demand to cut down the material cost which disturbs designers vastly. So they restart the study on resin material application on traverse base.

There are several points need to be considered when using resin material:

(1)Select proper material with high environmental resistance and high strength;

(2)Optimize structure designation, add additional ribs to abide deformation caused by environment change;

(3)Use Mold flow software analysis to optimize internal stress.

Through efforts and tests by designers, we have found out some materials which can be used in traverse base design [6]:

(1)Xarec DW140 series from Idemitsu Oil Development Co, Ltd, Japan;

(2)GR-40*0 series from Cheil Industries Inc;

(3)B4300 GS series from BASF.

These materials have good performance in strength, environmental resistance, drop test, etc. and they also have a lower price for production. With these material applied in traverse base production, it feeds back a 6\% 9\% cost down which is a good approach in the product design.

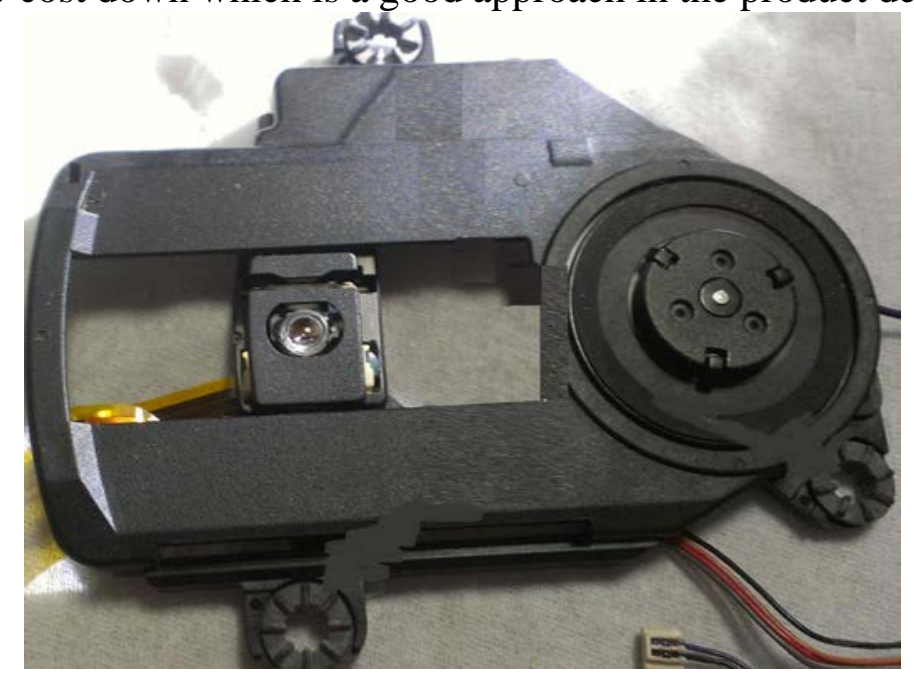

Fig. 4 Traverse base with resin material

\section{Conclusion:}

We discussed the merits and demerits of resin material in this paper compared with steel material and revealed the recent approach with resin material in productive practice. We also point out several important rules when using resin material. Several series materials are listed to give a guideline for new designers and new productors after our tests. With good application and design, it will show a 6\% 9\% costdown effect in traverse base design. We believe it will guide most productors to use resin material in their product design.

\section{References}

[1] Zhenhong Liu. Construction of Blue-ray Drive Adjustment Machine System [D]. Dalian: Dalian University of Technology, 2012.

[2] Wei xiong, Jianhua Mu, Dan Wang. Expectation for the Storage Density and the Data Rate of BD Disc [J], 2009. 
[3] Jian-she MA, Long-fa PAN, Ji-gang RU, Tian-shui ZHANG, Jun-bo CHEN. Dynamical Adjust Principle and Realization of Optical Axis Tilt Angle of DVD Traverse [J], 2004.

[4] Wei Guo. The Application Research of Traverse Base with Resin Material of BD Player [D]. Dalian: Dalian University of Technology, 2013.

[5] Zhiqiang Qu. Study on Digital Focus Control System of DVD [D]. Dalian: Dalian University of Technology, 2009.

[6] Wei Guo, Jianghua Zhang. Application of static tilt adjustment evaluation method in optical recording [J], 2015. 